\title{
Study of the influence of the exhaust line ultrasounds over the performance of the Blind Spot Warning System
}

\author{
Cătălin MEIROŞU ${ }^{1}$ \\ Universitatea Politehnica din București, Facultatea de Electronică, \\ Telecomunicatii și Tehnologii Informationale \\ 6meirosucatalin86@gmail.com
}

\begin{abstract}
During the previous years, the vehicle manufacturers have tried to equip their vehicles with as much technology as possible, making the driving experience for people easier than ever. Most of the modern vehicles come today with ADAS (Advanced Driver Assistance Systems) either for driving (E.g. Cruise Control, Blind Spot Warning) or Parking (E.g. Rear Ultrasonic Sensors, Rear View Camera). Since the vehicle come equipped with more technology, a major task in developing vehicle remains the integration of these ADAS system in the vehicle context with the other components. Since most of the components cope with each other on the vehicle level, some technologies are more affected by other components such as the case of an ultrasound vehicle scanning system (Blind Spot Warning) and the Exhaust line that emits ultrasounds from the exhaust muffler. The aim of this paper is to study the influence of the exhaust line ultrasounds (ultrasounds that are emitted by the engine cycle and filtered in the exhaust line of the vehicle) over the detection performance of the Blind Spot Warning Ultrasound system. Since vehicles are sold with a wide variety of powertrains, the solution presented took into account also these differences between powertrains equipped. In order to test the solution, mock-ups of the vehicle were made in order to proof the robustness of the method.
\end{abstract}

Keywords: ADAS, BSW, Blindspot, Ultrasounds

\section{Introduction}

This paper presents the performance influence of the Exhaust line of the vehicle on the performance of the Blind Spot Warning System. Also, the phenomenon will be explained along with the various configuration of the powertrains and the exhaust layouts that can directly affect the performance of the Blind Spot Warning detection. Tests have been carried out on a prototype vehicle to observe the sensor positioning impact for the Blind Spot Warning performance. 
The influence of the ultrasonic sensor positioning is observed in this paper, along with the various powertrain configurations that has a strong influence over the Blind Spot Warning detection performance. To determine the impact that the vehicle exhaust system has over the Blind Spot Warning detection on the prototype vehicle, the results of the preliminary tests based on a prototype vehicle will be presented. The prototype vehicle) will be tested in different sensor implementation scenarios and different filtering scenarios, so that the final position for the upcoming marketed vehicle - can be established. The influences of the exhaust ultrasounds over the Blind Spot Warning detection was tested for both prototype and final vehicle both on the test track but also on rolling road conditions for a better result interpretation. Moreover, various filtering scenarios were tested to establish the best performance for each setup, but also to discover the best suitable configuration for all powertrains that will equip the upcoming vehicle.

\section{Phenomenon explanation}

The false Blind Spot Warning detection scenario is described by a positive alert (The Blind Spot Warning System senses a vehicle in the blind spot) when no vehicle is present in the blind spot, as illustrated in Figure 1 below.

A false detection signals the driver by lighting up the light emitting diodes present in the side view mirror glass. An example of the false warning when there is no vehicle detected on the rear side is presented in the Fig. (1) below:

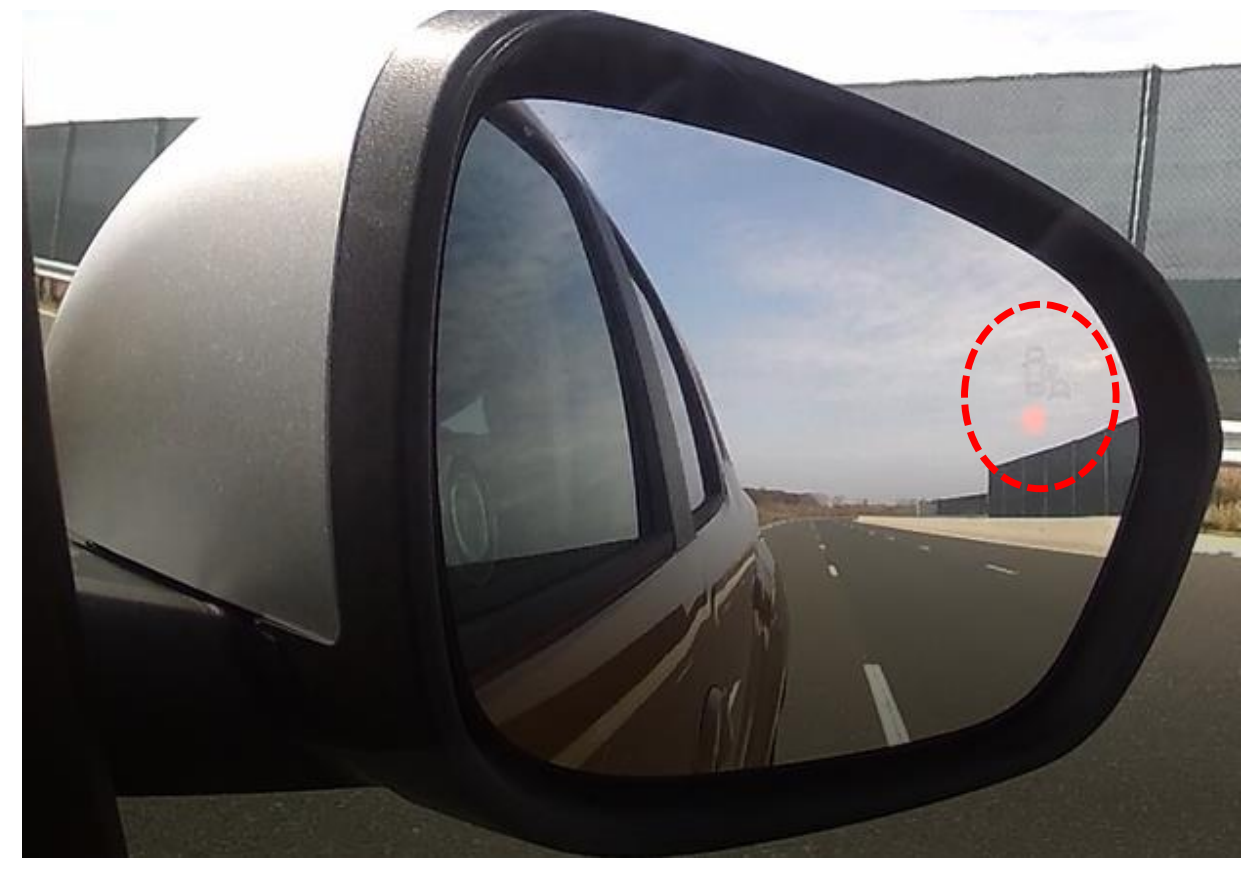

Figure 1. False warning alert example on the tested vehicle [1]

The false detection scenario for the prototype vehicle is repeated for a medium and high engine speed (rpm) at a certain torque level demanded by the driver 
(by pressing the accelerator pedal). In order to consider a clean detection (good vehicle detection), the Blind Spot Warning detection shall be centered in a $3 \mathrm{~m}$ $x 3 \mathrm{~m}$ square in the rear end of the leading vehicle, both right and left-side, as presented in the Fig. (2) below.

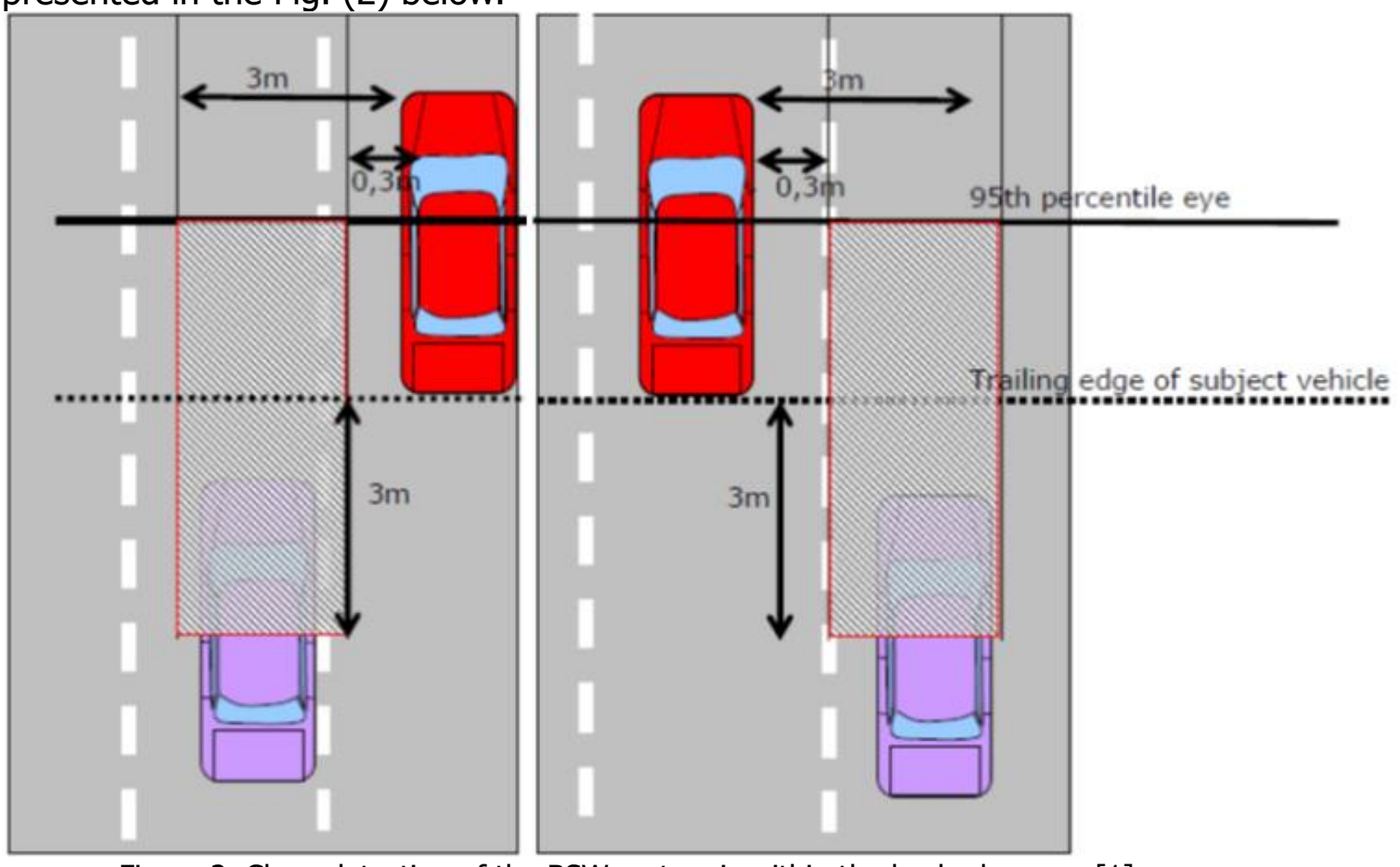

Figure 2. Clean detection of the BSW system is within the hashed square [1]

\section{Testing procedures}

\subsection{Testing track procedure}

In order to determine if the Blind Spot Warning detection is affected or not by the Exhaust noise and/or if a false detection may appear, the testing procedure will contain the following tests that simulate a possible driving scenario. This below-mentioned procedure comes to enforce the severity on the BSW system as the exhaust is being heated up during the consecutive tests and the exhaust gases increase in velocity as the exhaust heats up, this generating even more false detections. The testing procedure for testing the false detections contain the following tests:

1. Acceleration starting from standstill $(0 \mathrm{~km} / \mathrm{h})$ until $80 \mathrm{~km} / \mathrm{h}$ with $25 \%$ accelerator pedal pressed with a gear shift at $3000 \mathrm{rpm}$ for Diesel engines and $3500 \mathrm{rpm}$ for Gasoline engines. This test will repeat 3 times and the false detections will be noted down and compiled from the testing CAN recording.

2. Acceleration starting from standstill $(0 \mathrm{~km} / \mathrm{h})$ until $80 \mathrm{~km} / \mathrm{h}$ with $50 \%$ accelerator pedal pressed with a gear shift at $4000 \mathrm{rpm}$ for Diesel 
engines and $4500 \mathrm{rpm}$ for Gasoline engines. This test will repeat 3 times and the false detections will be noted down and compiled from the testing CAN recording.

3. Acceleration starting from standstill $(0 \mathrm{~km} / \mathrm{h})$ until $80 \mathrm{~km} / \mathrm{h}$ with $100 \%$ accelerator pedal pressed with a gear shift at $4500 \mathrm{rpm}$ (regulator engine speed) for Diesel engines and $6500 \mathrm{rpm}$ (regulator engine speed) for Gasoline engines. This test will repeat 3 times and the false detections will be noted down and compiled from the testing CAN recording.

4. Acceleration $50-110 \mathrm{~km} / \mathrm{h}$ starting from 3rd gear with $25 \%$ accelerator pedal pressed with a gear shift at $3000 \mathrm{rpm}$ for Diesel engines and 3500 rpm for Gasoline engines. This test will repeat 3 times and the false detections will be noted down and compiled from the testing CAN recording.

5. Acceleration $50-110 \mathrm{~km} / \mathrm{h}$ starting from $3 \mathrm{rd}$ gear with $50 \%$ accelerator pedal pressed with a gear shift at $4000 \mathrm{rpm}$ for Diesel engines and 4500 rpm for Gasoline engines. This test will repeat 3 times and the false detections will be noted down and compiled from the testing CAN recording.

6. Acceleration $50-110 \mathrm{~km} / \mathrm{h}$ starting from 3rd gear with $50 \%$ accelerator pedal pressed with a gear shift at $4500 \mathrm{rpm}$ (regulator engine speed) for Diesel engines and $6500 \mathrm{rpm}$ (regulator engine speed) for Gasoline engines. This test will repeat 3 times and the false detections will be noted down and compiled from the testing CAN recording.

7. Acceleration $80-130 \mathrm{~km} / \mathrm{h}$ starting from 4th gear with $25 \%$ accelerator pedal pressed with a gear shift at $3000 \mathrm{rpm}$ for Diesel engines and 3500 rpm for Gasoline engines. This test will repeat 3 times and the false detections will be noted down and compiled from the testing CAN recording.

8. Acceleration $80-130 \mathrm{~km} / \mathrm{h}$ starting from 4th gear with $50 \%$ accelerator pedal pressed with a gear shift at $4000 \mathrm{rpm}$ for Diesel engines and 4500 rpm for Gasoline engines. This test will repeat 3 times and the false detections will be noted down and compiled from the testing CAN recording.

9. Acceleration $80-130 \mathrm{~km} / \mathrm{h}$ starting from 4th gear with $100 \%$ accelerator pedal pressed with a gear shift at $4500 \mathrm{rpm}$ (regulator engine speed) for Diesel engines and $6500 \mathrm{rpm}$ (regulator engine speed) for Gasoline engines. This test will repeat 3 times and the false detections will be noted down and compiled from the testing CAN recording.

10. Acceleration from standstill $0-130 \mathrm{~km} / \mathrm{h}$ starting from $1^{\text {st }}$ gear with $50 \%$ accelerator pedal pressed with a gear shift at $3000 \mathrm{rpm}$ for Diesel engines and $3500 \mathrm{rpm}$ for Gasoline engines. This test will repeat 3 times and the false detections will be noted down and compiled from the testing CAN recording. This test scenario is also known as the Aggressive Level 1.

11. Acceleration from standstill $0-130 \mathrm{~km} / \mathrm{h}$ starting from 1 st gear with $100 \%$ accelerator pedal pressed with a gear shift at $4500 \mathrm{rpm}$ (regulator engine speed) for Diesel engines and $6500 \mathrm{rpm}$ (regulator engine speed) 
for Gasoline engines. This test will repeat 3 times and the false detections will be noted down and compiled from the testing CAN recording. This test scenario is also known as the Aggressive Level 2.

\subsection{Testing track results on the prototype vehicle}

The test results show false detections for the harshest testing scenarios for the powertrains mentioned, presented as below:

Aggressive level 1: acceleration from standstill $0-130 \mathrm{~km} / \mathrm{h}$ at $50 \%$ accelerator pedal press with gear changes at at $3000 \mathrm{rpm}$ for Diesel engines and $3500 \mathrm{rpm}$ for Gasoline engines

Aggressive level 2: acceleration from standstill 0-130 km/h at $100 \%$ accelerator pedal press with gear changes at at $4500 \mathrm{rpm}$ for Diesel engines and $6500 \mathrm{rpm}$ for Gasoline engines

For each powertrain available for the prototype vehicle, all the testing scenarios mentioned above have been carried out, with false detections for the aggressive level 1 and aggressive level 2 . Some powertrain configurations do not have any false detections and therefore it will not be presented.=

The powertrains that have been reported with false Blind Spot Warning detections are presented below:

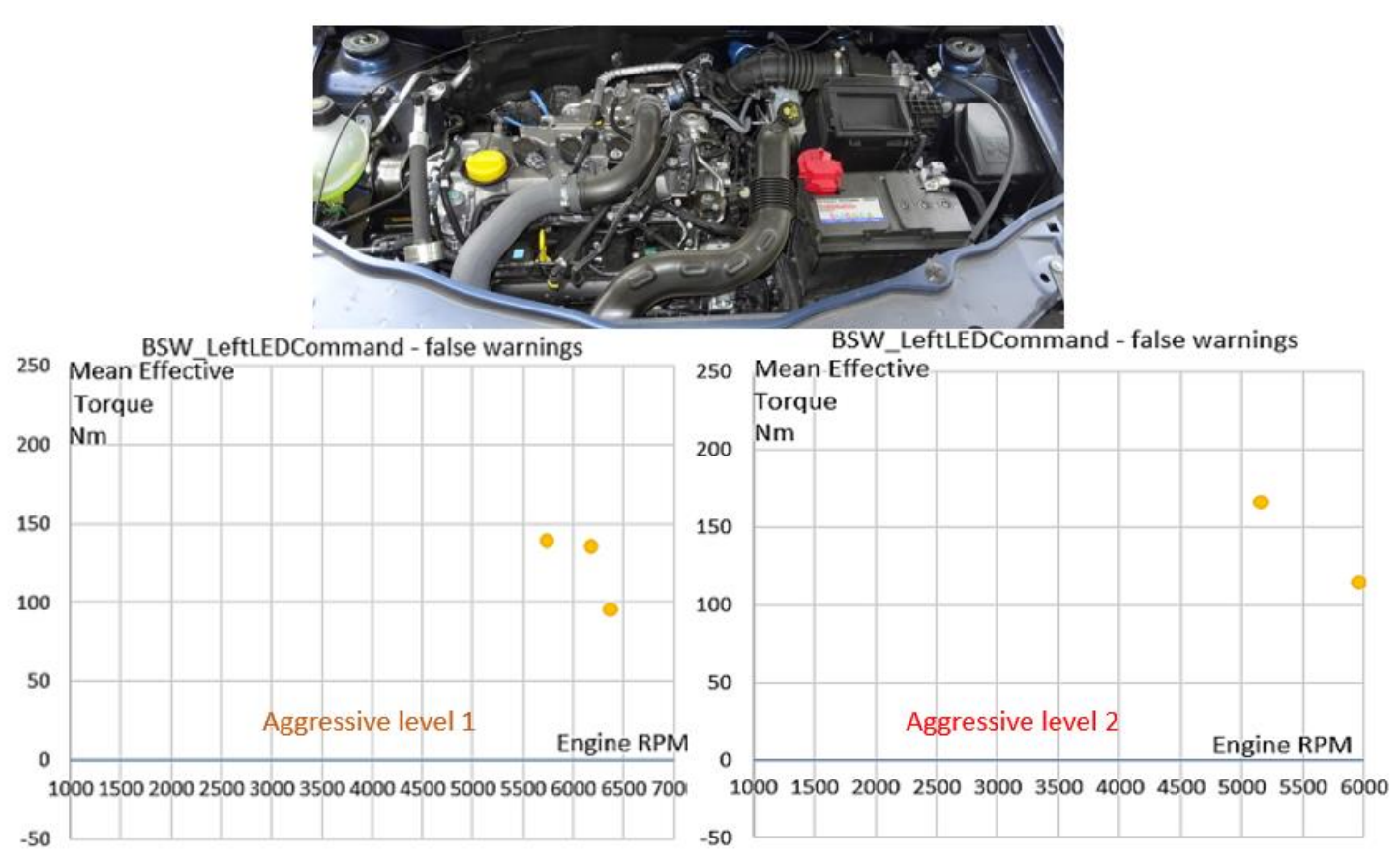

Figure 3. False detections for H5FT, 1.2-liter 16V Turbocharged Gasoline Euro 6 engine Aggressive level $1 \& 2[1]$ 


\subsubsection{Gasoline 1.2 liter Turbocharged Engine}

For this powertrain, the noise level is lower than in the case of a Diesel engine, as it can be seen in the graph below. This powertrain, however, does show some false detections for a very high engine speed (above $6000 \mathrm{rpm}$ ). Nevertheless, this engine speed is not so often used during day-by-day driving and can be considered insignificant.

In this case, due to the low incidence of the false detections both on aggressive level 1\&2, the false detection can be considered as the same between the two aggressive levels, even though during aggressive level 2 , the occurrence is lesser.

\subsubsection{Gasoline 2.0 liter Normally Aspirated Engine}

For this particular engine, used only in extreme cold areas (Russia, Ukraine and the Ex-Communist Russia block) and extreme hot areas (Golf countries, Persian Gulf, UAE, Arab countries), even though it is Natural aspirated (no turbocharger), the noise level is higher than the 1.2-liter engine, the principal differences between the two are:

Increased Engine Displacement (almost 0,8I)

Different exhaust line, including catalyst that is different from Euro4 to Euro6, the Euro 6 corresponding to 1.2-liter engine is more restrictive, therefore can be quieter.

Older technology, corresponding to lower requirements for the exhaust passby-noise regulations.

This engine has a very high noise level registered between 4500-5000 rpm, as it can be observed in the graph below. This engine speed range can be used by the drivers while overpassing or highway entries.

In this particular case, where a filtering is needed, the detection distance will drop with respect to the $4 \mathrm{~m}$ threshold established in the project requirements for the Blind Spot Warning system. For a lower aggressive level, a higher number of false detections can be observed in the 4500-5500 engine speed threshold.

For aggressive level 2, the use case in which more of the false detections shall happen due to a high engine speed and a high torque demand by the driver (remember that aggressive level 2 stands for $100 \%$ accelerator pedal pressed), the false detections as actually less frequent. This behavior is due to the fact that during Aggressive level 1, the echo sent by the exhaust is received by the BSW sensors as there is time to process the incoming ultrasounds. In the case of aggressive level 2, the engine speed increases so fast that the echo sent by the exhaust is ignored by the BSW sensors (the sample rate is faster than the processing sample of the BSW system). 


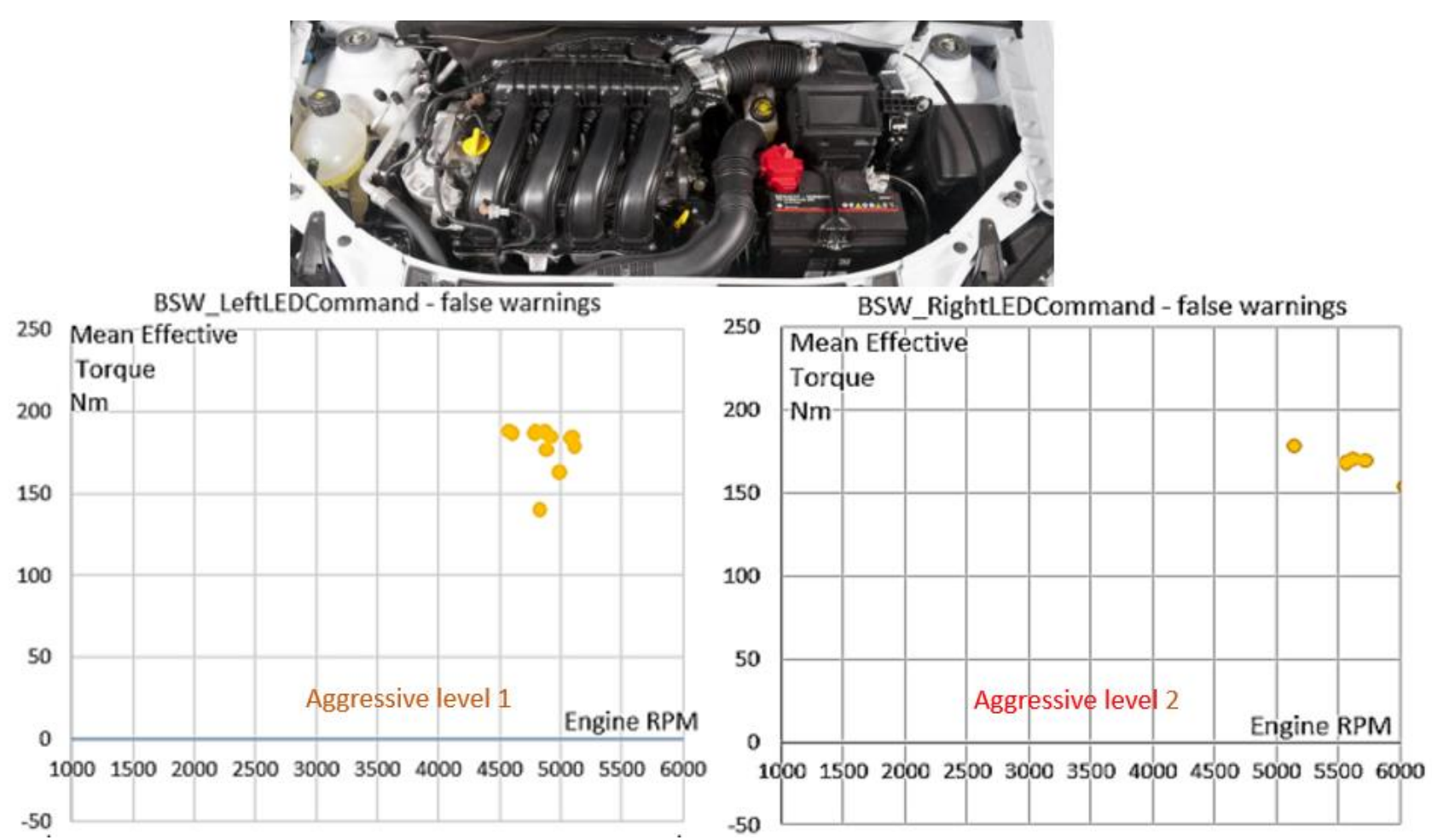

Figure 4. False detections for F4R, 2-liter 16V Gasoline Euro 4 engine - Aggressive level 1\&2

\subsubsection{Diesel 1.5 liter Turbocharged Euro 6 Engine}

For this 1.5-liter Euro 6 engine sold in the Northern-Africa region, it can be observed in the below figure that the false detection is very pronounced both on aggressive level 1 and aggressive level 2 . This is mainly due to the Exhaust line designed specifically for high temperatures and fast gas flow (in order not to maintain heat and help cooling).

As in the case of the F4R engine presented above, the occurrence of the false detections is lesser for aggressive level 2, as the BSW sensors have less time to process the echo coming from the Exhaust line, the sample rate of the BSW system being over the frequency of the exhaust noise.

However, this powertrain has a lot of occurrences for aggressive level 1 , in the engine speed threshold 3000-3800 rpm, this threshold being used by the drivers for overpassing or for highway acceleration lanes. This specific interval needs to be filtered out as the tests on the prototype vehicle show a very high probability that a false detection occurs. 


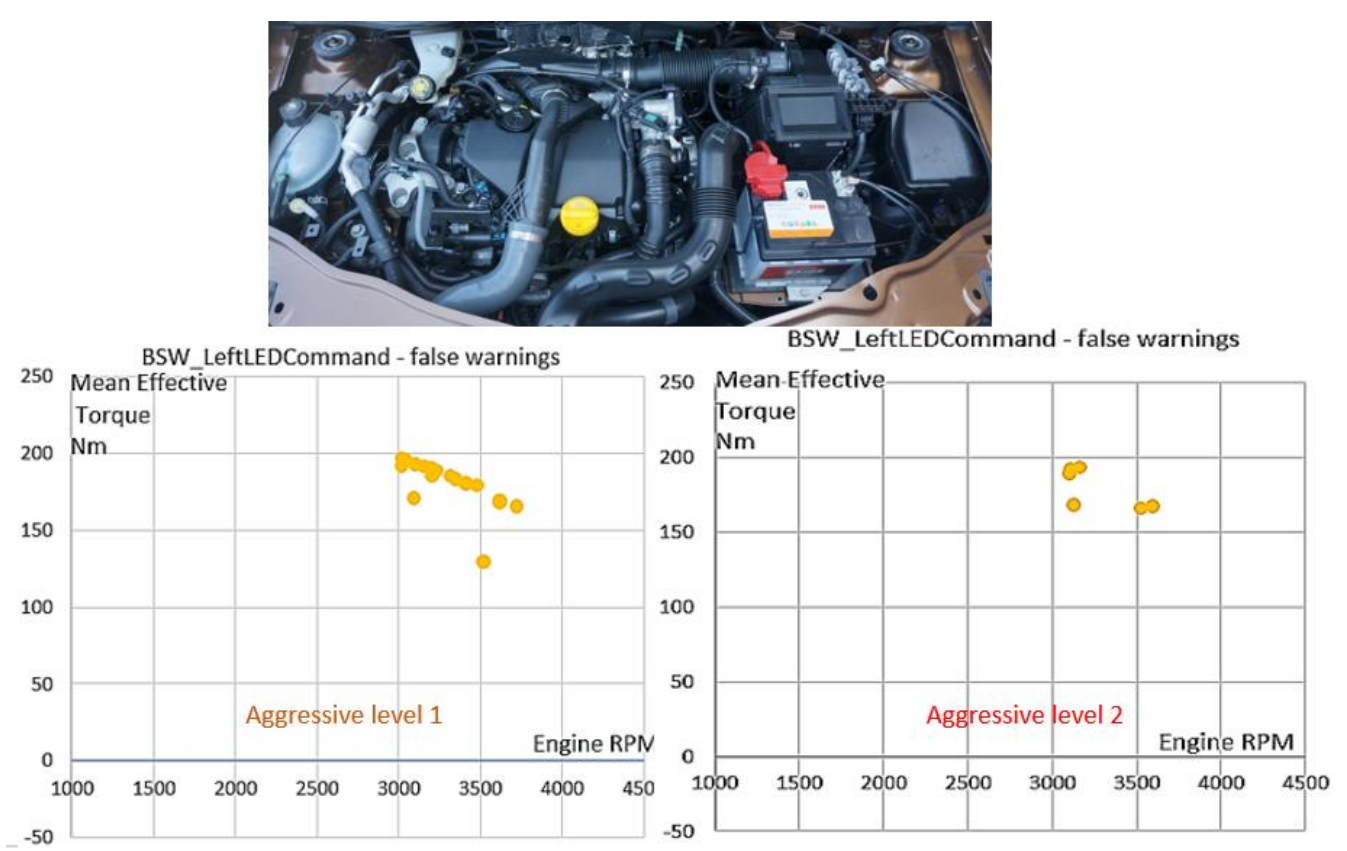

Figure 5. False detections for K9K 1.5-liter Gen 5 - Euro 6 Diesel Engine - Aggressive level 1\&2 [1]

\section{Diesel 1.5 liter Turbocharged Euro 6 B Engine}

This 1.5-liter Diesel engine is currently used on the vehicle, the vehicle that is sold with the studied BSW system. This calibration for the 1.5-liter DCI engine is made specifically for the European market, being a version that respect the harshest environmental $\mathrm{CO}_{2}$ regulations. In the figure below, it can be observed that for the same type of engine as above mentioned but only a new Software calibration and a new exhaust gas treatment system can influence so much the BSW detection.

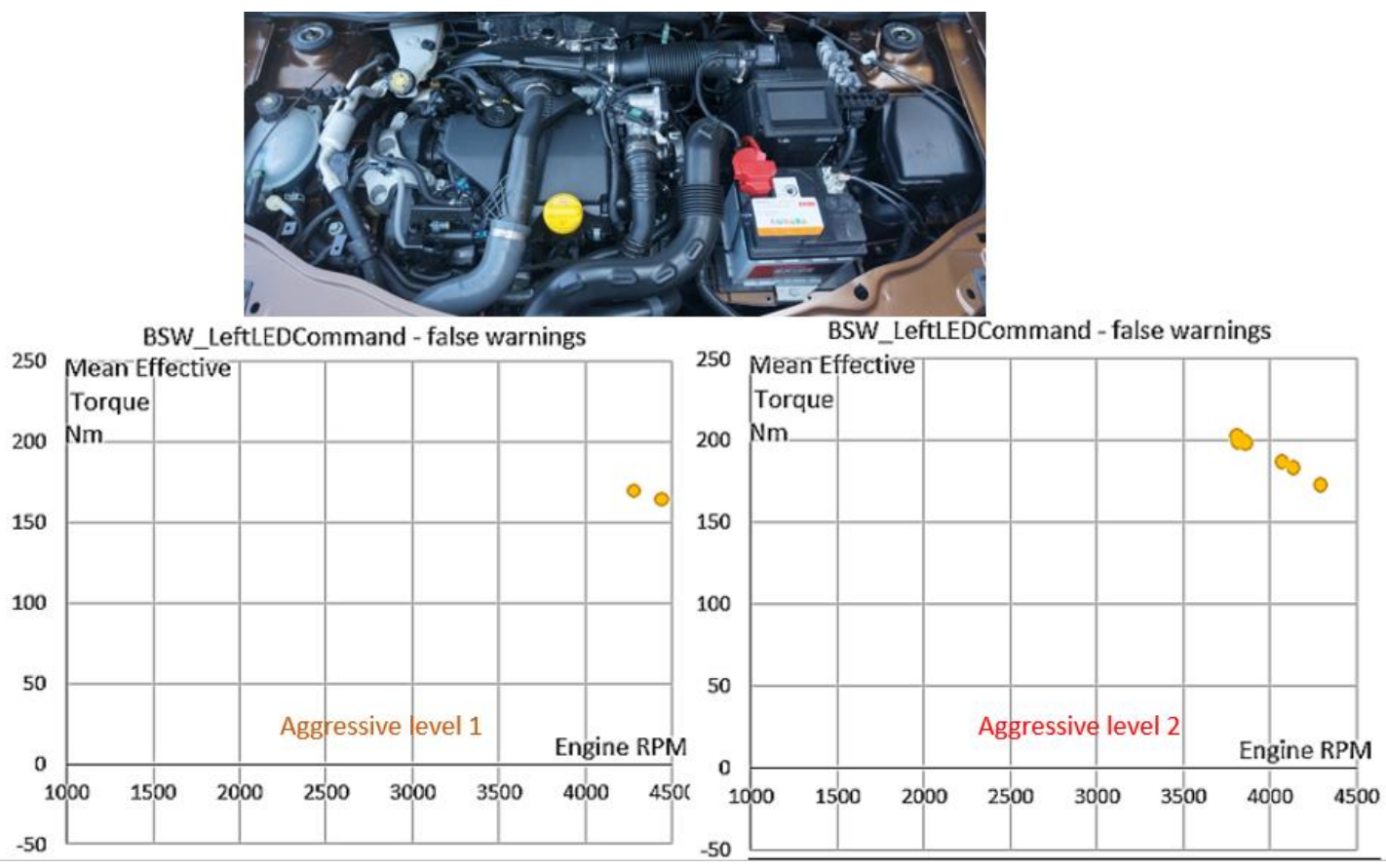

Figure 6. False detections for K9K 1.5-liter Gen 6 - Euro 6 Diesel Engine - Aggressive level $1 \& 2[1]$ 


\section{Preliminary test results}

The preliminary tests on this prototype vehicle show a different behavior of the false detections between a Diesel and Gasoline engines, the Diesel engine having false detections between $3500-4500 \mathrm{rpm}$, this being the usual engine speed during an overtaking. In the case of a Gasoline engine, the false detections appear in the threshold 6000-6500 rpm, a very high engine speed (close to the regulator cut-off). This Gasoline-engine false detection engine speed threshold is not used during day-to-day driving, even for extreme overpassing scenarios, as at this engine speed, the torque value is low and not efficient for overpassing.

These false detections are caused by the exhaust gases that generate some ultrasonic waves on the same frequencies as the operating frequencies of the Bosch ${ }^{\circledR}$ Blind Spot warning system. These exhaust gases ultrasounds are received as echo by the Ultrasonic sensors used by the BSW system and the system triggers the alert even though there is no vehicle present in the Blind Spot. A short schematic explaining the steps is presented in the Fig. (7):

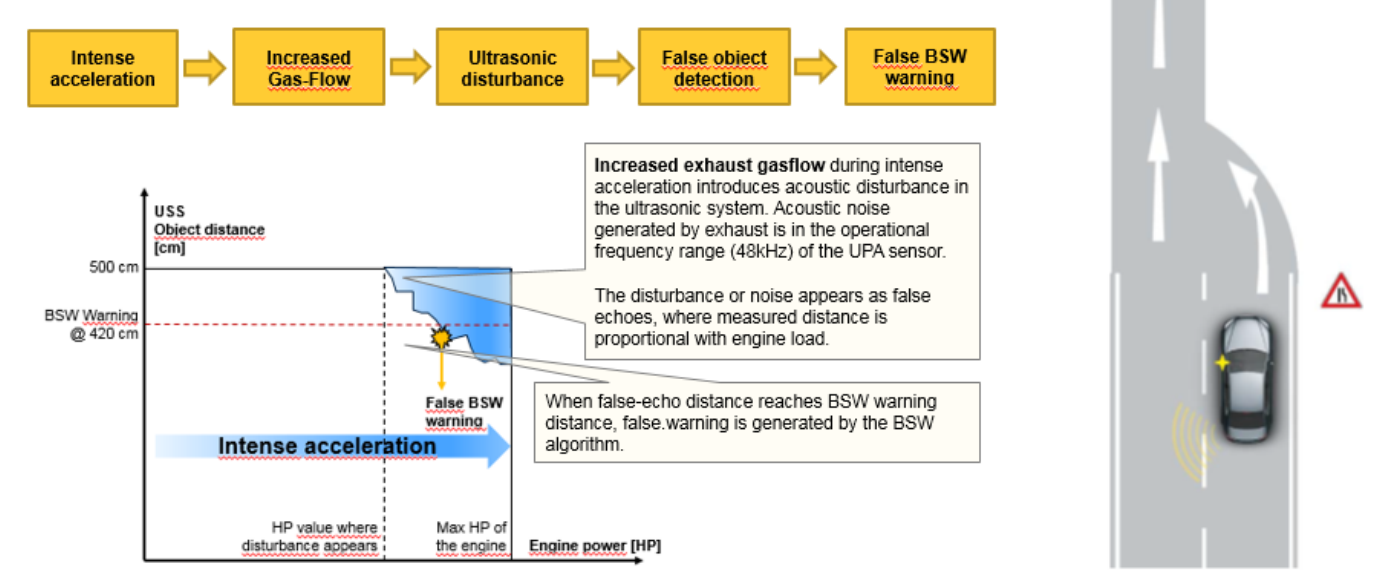

Figure 7. False BSW detection occurrence short explanation [1]

Solution

As seen above, multiple powertrains of the vehicles are affected by the false detection of the BSW system due to the ultrasounds generated by the various exhaust systems. Therefore, to sort out this flaw in detection, a transversal solution had to be developed. The best solution for this variety of powertrains is a software filter applied in the BSW ECU that ignores the false warnings coming as an echo from the exhaust. In order to obtain the data for building the software filter that can be applied successfully for all the powertrains, a data acquisition with an analog sensor mounted in the place of the rear sensor closest to the exhaust line was made. The results conducted on the prototype vehicles in TITU facility show the presence of false detections for a noise level above $98 \mathrm{~dB}(\mathrm{~A})$ - corresponding to $28 \mathrm{mV}$ in some scenarios, and a sure false detection for noise level above $104 \mathrm{~dB}(\mathrm{~A})$ - corresponding to $54 \mathrm{mV}$ on the analog sensor that measured the noise level. For a noise level in the threshold $98-104 \mathrm{~dB}(\mathrm{~A})$, the false detection is not confirmed all the time, since the ultrasound frequency duration as received as echo represents a short sample 
that is not processed by the system's sensors. Therefore, the filter must be applied for a noise level above $104 \mathrm{~dB}(\mathrm{~A})$, so that the occurrence of a false detection shall be as low as possible. In the figure below, it is represented a data acquisition result for a H5FT engine (1.2-liter Turbocharged Gasoline engine) showing the thresholds for possible and certain false detections occurrences.

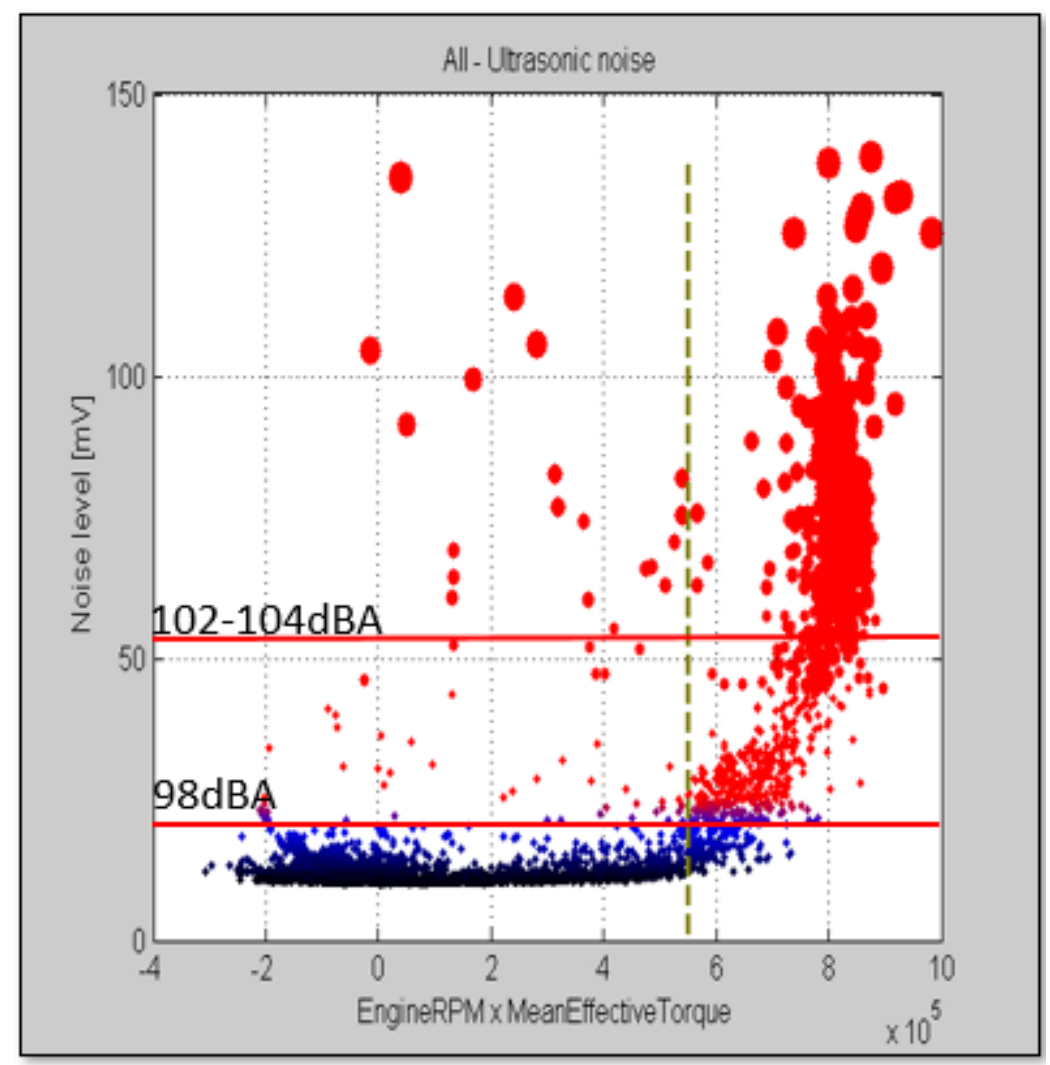

Figure 8. Exhaust noise level data acquisition for the H5FT engine (1.2-liter Turbocharged Gasoline engine) [1]

As it can be seen in the Fig. (8), all the points below $28 \mathrm{mV}$ or $98 \mathrm{~dB}(\mathrm{~A})$ is safe from influencing the performance of the Blind Spot Warning system, marked on the figure with small blue dots. For the threshold $28 \mathrm{mV}-54 \mathrm{mV}$, translated to a noise level between $98-104 \mathrm{~dB}(\mathrm{~A})$ marked with small red dots, there is a possibility that the false warnings can be triggered but the exhaust ultrasound emitting period is lower than the sample rate of the Blind Spot Warning system, this meaning that the Blind Spot Waning ultrasonic system may not be affected by the echo received for a noise level between 98-104 dB(A). For a noise level above $54 \mathrm{mV}$ (measured with the analog sensor), the false alerts are very likely to be triggered, therefore this noise level needs to be filtered.

As observed on the figure, some false warnings may happen also for low engine speeds $(3000 \mathrm{rpm})$, this being caused by a high torque demand on the driver's behalf for a high noise lever registered (over $100 \mathrm{mV}$ ). In most of the scenarios, the false detections happen after $5000 \mathrm{rpm}$ for this particular engine (H5FT), as it was shown in the real prototype tests presented in the chapters above. 
Since for these high engine speeds, the probability is higher for a false warning to occur, the filter shall be proposed to treat precisely these scenarios. In order to fully define the filter entirely, the data acquisition needs to be made for each powertrain and exhaust architecture used for the prototype and final series vehicle.

The software filter represents a compromise between not having false detection that may perturb the driver and the detection performance of the Blind Spot Warning system. Therefore, the tradeoff is false warnings for detection distance. Since the detection distance cannot be negotiated as there is also a minimum detection distance imposed by the NCAP advisory manual, the filter must comply with the $3 \mathrm{~m} \times 3 \mathrm{~m}$ detection distance. Below is a table that lists the correlation between the noise value obtained from the data acquisition and the maximum detection distance that the sensor can achieve for this particular noise without having any false warnings.

Table 1. Correlation between Sensor noise level and the maximum detection distance [1]

\begin{tabular}{|l|l|}
\hline $\begin{array}{l}\text { Noise value } \\
{[\mathbf{m V}]}\end{array}$ & $\begin{array}{l}\text { Detection range } \\
{[\mathrm{cm}]}\end{array}$ \\
\hline 100 & 230 \\
\hline 90 & 237 \\
\hline 80 & 244 \\
\hline 70 & 250 \\
\hline 60 & 285 \\
\hline 50 & 315 \\
\hline 40 & 350 \\
\hline 30 & 400 \\
\hline 20 & 450 \\
\hline 10 & 500 \\
\hline
\end{tabular}

As presented above, to respect the requirements given by the project and imposed by NCAP $尺$ for being allegeable in scoring points in their rating system, the noise level must be maximum $54 \mathrm{mV}$ at sensor level. The table also shows that the lower the noise, the longer the detection distance can be achieved without any false warnings.

The filter also shall take into consideration the engine speed (direct influence on the exhaust line noise) but also on the engine torque as the demand from the engine can also influence the exhaust noise by changing the timing and advance laws on the engine injection process (more Diesel/Gasoline injected, adding more air means the burn inside the engine amplifies which turns to a higher-pressure difference, meaning exhaust noise).

For each powertrain and exhaust architecture, a separate filter characteristic is built, a typical filter can be seen in the figure below. This filter takes into 
consideration the two variables - engine speed and torque demanded but also the noise level acquired at sensor level.

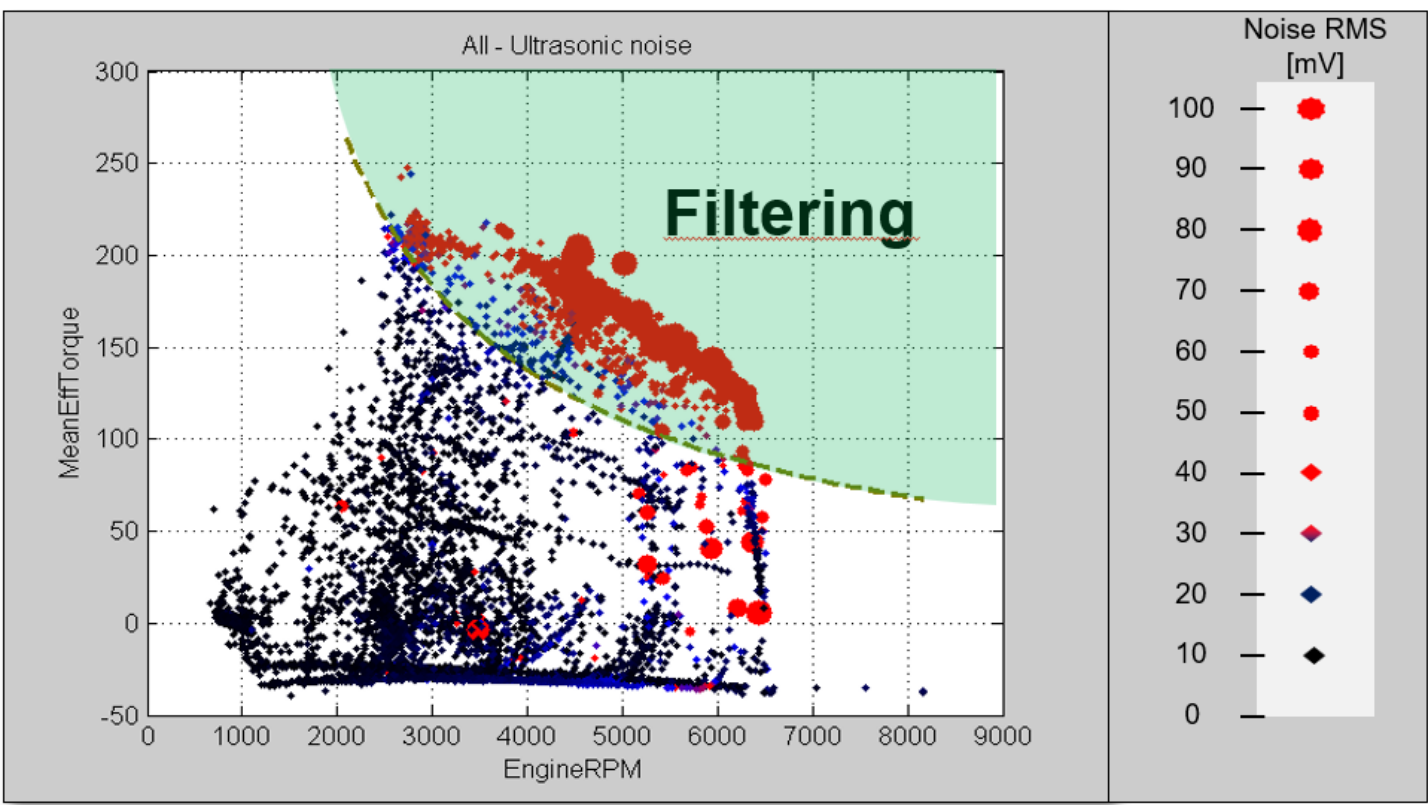

Figure 9. Exhaust noise filter applied on the H5FT (1.2-liter Turbocharged Gasoline engine)

In this case, the large red dots are delimited by a hyperbole between 4000 $6500 \mathrm{rpm}$ and $100-200 \mathrm{Nm}$ of torque demanded. This is the particular area on which the filter will cut out the frequencies received as echo from the exhaust line, so that it doesn't report false warnings. Outside this hyperbole, towards the lower left corner of the chart, the Blind Spot Warning system is working properly by the required specifications.

\section{Conclusions}

For the theme studied - the influence of the exhaust ultrasounds over the Blind Spot Warning ultrasound-based detection system, the following tests and research has been carried on:

Tests on the former body-type prototype vehicle with the current installed position and sensors on the TITU tracks and on rolling-road conditions.

Tests on all the possible powertrains and exhaust architecture existing that covers all the range of the sold vehicle worldwide.

$6000 \mathrm{~km}$ of road testing in normal traffic conditions, based on a test track that covered most of the current driving conditions in Europe.

Testing in rolling road conditions with another 2 different vehicles to confirm and compare the results.

Testing on all 4 seasons and for all types of weather in order to cover all possible conditions that are met in Europe. 
Aerodynamic simulations for establishing the best positions for the Blind Spot Warning ultrasound sensors.

Numerical simulations to determine the precise pattern of detection for the rear sensors so that the implementation is a success.

Developing a filter that takes into account two main parameters of the powertrain - engine speed and torque demanded.

Testing with and without a Software filter in order to spot the differences between the two conditions.

These all together conclude that the system used on the sold vehicle is a reliable system that can be used in most of the weather conditions (except rain and wet surface), on most of the paved roads existing in Europe, and on all possible sold powertrains. However, the system has some limitations due to the filtering but only under heavy acceleration.

Since not all the research leads have been studied, this including the rear mud guards, larger exhaust pipes and new prototype catalysts have been studied, the thesis can be a departure point for studying the influence of these elements in the attenuation of false detections for the Blind Spot Warning ultrasound system on the sold vehicle. Also, a very important influence is the temperature rise in the exhaust line caused by extreme engine speed, but also very high external temperatures $\left(>37^{\circ} \mathrm{C}\right)$ that causes sudden false warnings for normal driving conditions even though there is no vehicle in the blind spot at that time.

\section{Further work}

While studying the phenomenon and testing different powertrain layouts and engines, a very interesting aspect was the different behavior for the same engine but different power output calibrations. Besides this, the study for other solutions was not approved for the following leads:

- Rear mud guards for all the vehicles equipped with the Blind Spot Warning system. These additional plastic covers were mounted on the rear side of the wheel arch and prevents the water mist to be gathered around the Blind Spot Warning sensor. This solution could provide a decent protection against false detections. Since the mud guards were not tested and represented an additional cost not taken into account at the beginning of the design phase of the vehicle, this solution was abandoned before the test were started.

- New catalysts, middle silencers and final silencers. Since the whole noise level is to be attenuated by the silencers and the catalyst, the development of new exhaust lines in 2 years-time since the problem was discovered until the vehicle was first sold was not possible nor approved by the project. This solution could have solved the problem only if the whole exhaust system was built to treat this particular problem. But since there are also other requirements form the exhaust system, this problem could not convince the board to accept the budget for the modification. The modification of the whole exhaust lines for all the powertrains was more difficult and expensive than the whole vehicle testing, therefore it was abandoned. 
- Larger dimension for the exhaust pipes. This solution was suggested by the $\mathrm{NVH}$ testing team that had an expertise with the exhaust noise level for the audible threshold. The larger the diameter of the exhaust pipes, the lower the noise level since the flow section is bigger and the exhaust gas speed can decrease, this causing less ultrasound frequencies emitted on the muffler. However, this solution also has its drawbacks for the NVH exterior noise homologation, as a larger diameter means a higher resonance, therefore a higher noise level on the rolling road homologation. Since the homologation is crucial for vehicle selling, this solution was also abandoned.

\section{Acknowledgement}

The work has been funded by the Operational Program Human Capital of the Ministry of European Funds through the Financial Agreement 51675/09.07.2019, SMIS code125125

\section{References}

[1] Renault Technologie Roumanie, Titu - Blind Spot Warning implementation on the HJD Project 2016-2017

[2] Bosch Engineering Center Cluj, Cluj-Napoca - Development of the Blind Spot Warning System for the HJD project 2016-2017

[3] Renault Technocentre Guyancourt - Development of Engines and Powertrains

[4] EuroNCAP Official European New Car Assessment Programme - Ratings 